Check for updates

Cite this: RSC Adv., 2019, 9, 22220

Received 18th June 2019

Accepted 8th July 2019

DOI: 10.1039/c9ra04567h

rsc.li/rsc-advances

\section{All solid state rechargeable aluminum-air battery with deep eutectic solvent based electrolyte and suppression of byproducts formation}

\begin{abstract}
Ryohei Mori (iD *ab
In order to create a rechargeable aluminum (Al)-air battery, an aluminum-air battery with a deep eutectic solvent-based solid electrolyte was prepared. The prepared battery demonstrated a capacity smaller than the theoretical value although we observed stable electrochemical reactions. When TiN was used as an air cathode material, byproducts of the aluminum-air battery such as $\mathrm{Al}(\mathrm{OH})_{3}$ and $\mathrm{Al}_{2} \mathrm{O}_{3}$ were not detected on either the Al anode nor the air cathode. Even though we did not detect byproducts, we observed $\mathrm{NaCl}$ and $\mathrm{NH}_{4} \mathrm{Cl}$ phases on the air cathode, and they did not hinder the electrochemical reaction.
\end{abstract}

\section{Introduction}

Advanced materials that permit the efficient harvesting, storage, and utilization of renewable energy are at the heart of ongoing research in the energy field. ${ }^{1-4}$ To date, $\mathrm{Li}$ ion batteries are the most successful energy-storage solution; they have been widely used in both portable electronics and electric vehicles (EVs) since the first report was made on them in 1991. Unfortunately, their limitations of high cost, insufficient energy density, and unsatisfactory safety have prevented their large-scale applications in the automobile industry, especially for extended-range EVs. ${ }^{5,6}$ In this regard, many post-lithium-ion technologies, including $\mathrm{Li}-\mathrm{S},{ }^{7} \mathrm{Na}$ ion, ${ }^{8}$ all-solidstate $\mathrm{Li}$ ion batteries, ${ }^{9}$ and metal-air batteries, have been proposed and actively studied. ${ }^{10,11}$ Recently, metal-air batteries have become a promising power source because of their high theoretical energy density and their use of atmospheric oxygen as fuel. ${ }^{12-15}$ Among various metal-air batteries, alkaline metal-air batteries, especially lithium-oxygen, have been intensively investigated because of their high specific energy density of up to $5200 \mathrm{~W} \mathrm{~h} \mathrm{~kg}^{-1}$. However, the rechargeability, safety, and cost of these batteries make them difficult to commercialize. In addition, lithium is very sensitive to ambient conditions, such as humidity and oxygen, and it is a scarce natural resource in some regions. ${ }^{16,17}$

Meanwhile, aluminum (Al) is inexpensive, safe, and is the third most abundant element in the Earth's crust. An aluminumbased redox couple, which involves a three-electron transfer that occurs during the electrochemical charge/discharge reactions, provides a storage capacity that rivals that of the single-electron lithium-ion battery. Its relatively low atomic weight of 26.98 and trivalent state confer it a gram-equivalent weight of 8.99 and

${ }^{a}$ Green Science Alliance Co., Ltd., 2-22-11 Obana, Kawanishi City, Hyogo Prefecture 666-0015, Japan

${ }^{b}$ Fuji Pigment Co. Ltd, 2-23-2 Obana, Kawanishi City, Hyogo Prefecture 666-0015, Japan. E-mail: moriryohei@fuji-pigment.co.jp; Fax: +81-72-759-9008; Tel: +81-72-759-8501 an electrochemical equivalence of $2.98 \mathrm{~A} \mathrm{~h} \mathrm{~g}^{-1}$, as compared with $3.86 \mathrm{~A} \mathrm{~h} \mathrm{~g}^{-1}$ for lithium. Because of its lower reactivity, easier handling, and greater safety, such an Al-based battery may offer significant cost savings and safety improvements over Li ion batteries. Consequently, the use of $\mathrm{Al}$ as anode in metal-air batteries has long attracted attention because of its high theoretical ampere hour capacity and overall specific energy. In addition, $\mathrm{Al}$ is the most recycled metal on the planet and is economically cheap compared with lithium, zinc, and magnesium. A major barrier preventing the commercialization of $\mathrm{Al}-$ based batteries is the high rate of aluminum self-corrosion in alkaline solutions under both open-circuit and discharge conditions. Furthermore, byproducts such as $\mathrm{Al}_{2} \mathrm{O}_{3}$ and $\mathrm{Al}(\mathrm{OH})_{3}$ accumulate at both the anode and cathode, which also suppress electrochemical reactions. ${ }^{18-22}$ A number of studies have been reported regarding aluminum-air batteries using aqueous, organic solvents, and ionic-liquid-based electrolytes, and some of these have been shown to exhibit rechargeable properties. In particular, when an ionic liquid-based electrolyte was used, the aluminum-air battery began to demonstrate rechargeable battery behavior. ${ }^{23-29} \mathrm{An}$ ionic analog electrolyte based on $\mathrm{AlCl}_{3}$ and urea has been developed as a deep-eutectic-based electrolyte, and it has been found to exhibit rechargeable behavior and a cost advantage over ionic liquid-based electrolytes. ${ }^{30,31}$ However, when one considers creating an aluminum-air battery for practical use, a solid-state battery is desirable because of its toughness and ease of manufacturing, which may also result in a low-cost battery. Furthermore, ionic-liquid-based electrolytes that are used should be non-volatile although we have observed that ionic-liquidbased electrolytes evaporate completely after a few months even under an ambient atmosphere at room temperature.

In this study, we showed that a solid-state, rechargeable aluminum-air battery with stable electrochemical reactions could be achieved by mixing $\mathrm{AlCl}_{3}$, urea, carboxymethyl cellulose (CMC), and glycerin for use as an electrolyte. 


\section{Experimental}

An aluminum (Al) board (A1050, 99.5\% purity) was used as an anode. To prepare the air cathode, titanium nitride (TiN) and polyvinylidene difluoride (PVDF) at $1: 0.3$ molar ratio were mixed, compressed with a pelletizer at $30 \mathrm{MPa}$, and used as a pelletshaped air cathode. SUS 304 mesh was used as the electricalcurrent collector. $\mathrm{AlCl}_{3}$, urea, $\mathrm{CMC}$, and glycerin at $3: 2: 1: 1$ molar ratio were mixed, and commercial gauze was soaked in this mixture for use as a solid electrolyte. For the preparation of the solid-state aluminum-air battery, the aluminum (Al) board, solid electrolyte, air cathode, and SUS 304 mesh were assembled in that order and clamped using a plastic clip. A schematic figure of the aluminum-air battery prepared in this study is shown in Fig. 1. All of the aforementioned chemicals were purchased from Sigma Aldrich Corporation (Saint Louis, USA). The electrochemical performance of the battery was evaluated by using a galvanostat (SP-150; BioLogic, France). The measured area of the prepared aluminum-air battery was $1 \mathrm{~cm}^{2}$ for both the anode and air cathode. Cyclic voltammetry was carried out at a scan rate of $10 \mathrm{mV} \mathrm{s}^{-1}$. All electrochemical measurements were made under ambient atmospheric conditions at $25{ }^{\circ} \mathrm{C}$ and $40 \%$ humidity. Crystalline phases of the anode and air cathode were studied by $\mathrm{X}$ ray diffraction (XRD) on a RAD-RU diffractometer (Rigaku Corp., Tokyo, Japan) using $\mathrm{Cu} \mathrm{K} \alpha$ radiation at $40 \mathrm{kV}$ and $200 \mathrm{~mA}$. X-ray photoelectron spectroscopy (XPS) measurements were carried out on a PHI5000 Versa Probe II spectrometer (Ulvac-Phi Inc. MN, USA). The morphology and energy-dispersive X-ray spectroscopy (EDS) analysis of the air cathode was performed using a field emission scanning electron microscope (JSM-7610F, JEOL Ltd., Japan) with an acceleration voltage of $15 \mathrm{kV}$.

\section{Results and discussion}

Fig. 2 presents the charge-discharge curve of the prepared solidstate aluminum-air battery at an applied current of $0.1 \mathrm{~mA}$ $\mathrm{cm}^{-2}$, for which the cutoff voltage was $0.2-1.5 \mathrm{~V}$. Although the capacity was as small as $35.8 \mathrm{~mA} \mathrm{~h} \mathrm{~g}^{-1}$ at the first cycle, it remained at $35.0 \mathrm{~mA} \mathrm{~h} \mathrm{~g}{ }^{-1}$ even after 50 charge-discharge

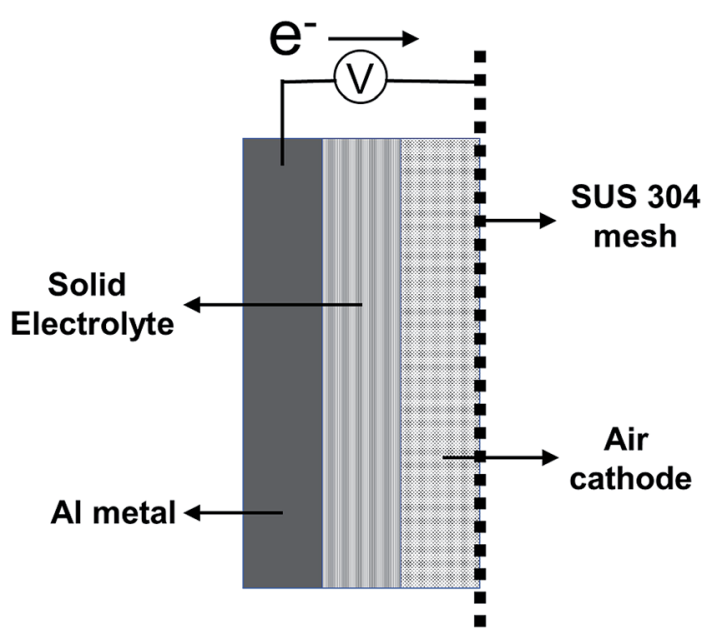

Fig. 1 Schematic figure of Al-air battery prepared in this study. cycles, indicating that $97.8 \%$ of the initial capacity was maintained. It is clear that although the capacity was smaller than the theoretical value, it was stable even after a large number of charge-discharge electrochemical reactions.

The cyclic voltammograms of the prepared solid-state aluminum-air battery at the first and 25th cycles are presented in Fig. 3. The cycle was measured between 0 and $2.0 \mathrm{~V}$, which were used to characterize the redox reactions. Conspicuous anodic or cathodic peaks were not observed, although a stable cyclic voltammetry confirming the stability of TiN as catalytic air cathode materials was observed over repeated cycles. These results and the profile of the cyclic voltammogram were similar to those found in our previous study, in which TiN was also used as an air cathode material for an aluminum-air battery. In our previous study, we used a mixture of 1-butyl-3methylimidazolium chloride and $\mathrm{AlCl}_{3}$ as an electrolyte. It is interesting to note that ionic-liquid-based electrolytes and deepeutectic solvent-based electrolytes demonstrated similar cyclic voltammetry profiles, which suggest a resemblance of the electrochemical reactions of these two types of electrolytes.

Chloroaluminate melts are well known for their high affinity to aluminum electrodeposition and have been considered as possible electrolytes for the development of secondary $\mathrm{Al}$ ion batteries. $^{32-35}$ This type of electrolyte can be basic, neutral, or acidic depending on the molar ratio of $\mathrm{AlCl}_{3}$ that is used. In basic melts, both $\mathrm{AlCl}_{4}{ }^{-}$and $\mathrm{Cl}^{-}$species coexist, whereas in neutral melts, the only anionic species is $\mathrm{AlCl}_{4}{ }^{-}$. In acidic melts, the predominant species is $\mathrm{Al}_{2} \mathrm{Cl}_{7}{ }^{-}$, and the $\mathrm{Al}$ deposition/ stripping process is as follows:

$$
4 \mathrm{Al}_{2} \mathrm{Cl}_{7}^{-}+3 \mathrm{e}^{-} \leftrightarrow \mathrm{Al}+7 \mathrm{AlCl}_{4}^{-}
$$

In this case, this electrochemical reaction is reversible and is said to be utilizable for a rechargeable aluminum-air battery ${ }^{\mathbf{3 6}}$

The mechanism of the ORR/OER reaction in ionic liquidbased electrolytes remains complex, however, and it has not yet been completely elucidated. Recently, some urea- and acetamide-based deep-eutectic solvents developed by Abood et al. have been shown to present appropriate reversible activity for $\mathrm{Al}$ deposition/stripping. ${ }^{37}$ Here, the amide group reacts with $\mathrm{AlCl}_{3}$ and creates a positively charged complex and negatively charged tetrachloroaluminate anion:

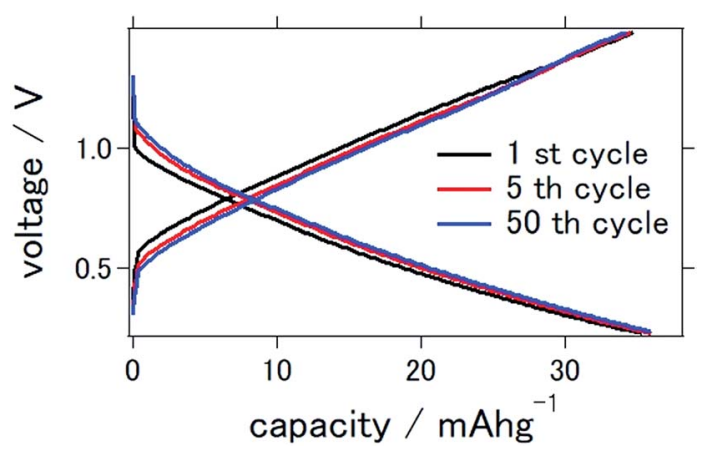

Fig. 2 Charge-discharge curves of the all solid state Al-air battery with TiN air cathode prepared in this study. 


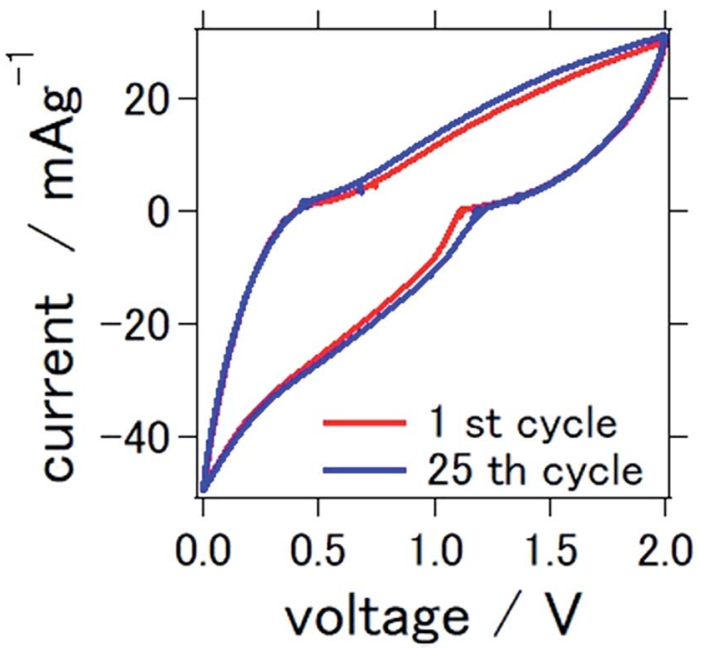

Fig. 3 Cyclic voltammetry of the all solid state Al-air battery with TiN air cathode prepared in this study.

$$
2 \mathrm{AlCl}_{3}+n \text { Amide } \leftrightarrow\left[\mathrm{AlCl}_{2} \cdot n \mathrm{Amide}^{+}+\mathrm{AlCl}_{4}{ }^{-}\right.
$$

Even with the above descriptions, we are not sure at this stage what is the exact ion species or charge carrier for our aluminum-air battery system, although we can assume that it is $\mathrm{AlCl}_{4}{ }^{-}$or $\mathrm{Al}_{2} \mathrm{Cl}_{7}{ }^{-}$. Katayama et al. stated that in the case of the aluminum-air battery with an electrolyte composed of a mixture of $\mathrm{AlCl}_{3}$, 1-butyl-3-methylimidazolium chloride, and bis(trifluoromethylsulfonyl)amide, the charge carrier should be either $\mathrm{AlCl}_{4}{ }^{-}$or $\mathrm{Al}_{2} \mathrm{Cl}_{7}{ }^{-}$. They claim that when the concentration of $\mathrm{Al}_{2} \mathrm{Cl}_{7}{ }^{-}$decreases, the concentration of $\mathrm{AlCl}_{4}{ }^{-}$increases; this was confirmed by Raman spectroscopy. ${ }^{38}$ Agiorgousis et al. excluded the possibility of the $\mathrm{Al}^{3+}$ cation as the charge carrier and instead presented the $\mathrm{AlCl}_{4}{ }^{-}$anion as the possible charge carrier. ${ }^{39}$ Furthermore, Angell et al. claimed that both $\mathrm{Al}_{2} \mathrm{Cl}_{7}{ }^{-}$ and $\mathrm{AlCl}_{4}{ }^{-}$exist in the $\mathrm{AlCl}_{3}{ }^{-}$urea ionic liquid analog electrolyte. ${ }^{30}$ Since the electrolyte contains other additives in our aluminum-air battery system such that the electrochemical mechanism may be even more complicated than the aforementioned systems, it should be further investigated in future studies. The capacity of our rechargeable aluminum-air battery is lower than the theoretical value proposed for an aluminumair battery. This may be mainly due to insufficient contact between the electrode and solid electrolyte, as well as our nonideal battery preparation technique.

Additionally, we could not exclude the possibility that the small observed capacity is due to the fact that our current battery system is not wholly an aluminum-air battery, but also partly an aluminum ion battery. We infer that the pellet-shaped air cathode that was prepared by compressing powder with quite strong force is very much tightly pressed. So that the ambient air might not penetrate into entire air cathode sufficiently in order to react with the charge carrier that is provided by the electrolyte. Measuring the electrochemical properties in a $\mathrm{N}_{2}$ atmosphere could help understand this mechanism. By the way, it should be noted here that besides the use of $\mathrm{AlCl}_{3}$ and urea as an electrolyte, CMC was added as a viscosity thickener to prepare a solidified electrolyte. In addition, the authors and Chen et al. have reported that deep eutectic solvents are volatile. ${ }^{40}$ Therefore, glycerin was added as a humectant for the solid-state electrolyte in our battery system. The $\mathrm{AlCl}_{3} /$ urea/ CMC/glycerin molar ratio was $3: 2: 1: 1$, since this components ratio demonstrated suitable viscosity for a solid electrolyte. However, more appropriate component ratios may be elucidated in further studies to enhance battery performance. It should be mentioned here that the deep-eutectic solvent-based electrolyte was quite stable because its electrochemical properties did not deteriorate even after 1 month following battery preparation (data not shown).

Fig. 4 shows the X-ray diffraction patterns of the $\mathrm{Al}$ anode and air cathode before and after the electrochemical reaction. CD denotes the charge-discharge electrochemical reaction. Fig. 4(a) shows the XRD of the Al anode before and after the electrochemical reaction. As can be observed, it is clear that the byproducts $\mathrm{Al}(\mathrm{OH})_{3}$ and $\mathrm{Al}_{2} \mathrm{O}_{3}$ were not observed. This phenomenon is similar to what was shown in previous studies in which $\mathrm{Al}$ deposition was possible at room temperature when an ionic-liquid-based electrolyte was used instead of an aqueous electrolyte. ${ }^{26-28}$ In addition, when TiN was used as an air cathode, the byproducts of the aluminum-air battery, such as $\mathrm{Al}(\mathrm{OH})_{3}$ and $\mathrm{Al}_{2} \mathrm{O}_{3}$, were not observed (Fig. 4(b)). This agrees with our previous study in which TiN was applied as an air cathode material and butyl methyl imidazolium chloride was used as an ionic-liquid electrolyte. ${ }^{27}$ It is interesting to note that when a deep eutectic solvent was used as an electrolyte, similar results were also obtained. As far as we know, this study

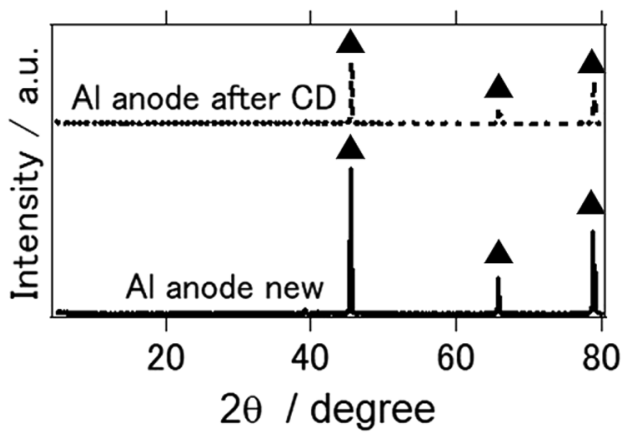

(a)

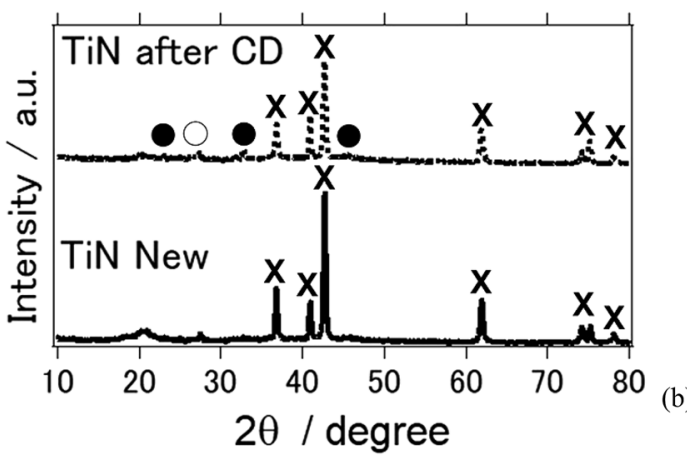

Fig. 4 X-ray diffraction patterns of the all solid state Al-air battery (a) Al anode (b) TiN air cathode before and after the electrochemical reaction. ( $\mathbf{\Delta}$ : Al metal, $\times$ : TiN, $\bullet: \mathrm{NH}_{4} \mathrm{Cl}, \mathrm{O}: \mathrm{NaCl}$ ). 
confirms for the first time that byproducts are not observed on either the $\mathrm{Al}$ anode nor the air cathode when a deep-eutectic solvent-based electrolyte is used in place of an ionic-liquidbased electrolyte. It should be noted that we observed $\mathrm{NaCl}$ and $\mathrm{NH}_{4} \mathrm{Cl}$ phases, which are suggested to have formed as a result of the electrochemical reaction in our aluminum-air battery system.

Fig. 5 shows the EDS analysis of the air cathode surface before and after the electrochemical reaction. Table 1 summarizes the data of the EDS analysis at two points to ensure the accuracy of this measurement. It should be noted here that the obtained EDS results were similar between the two points on the air cathode surface, which confirms the accuracy of our measurement. C, N, F, and Ti were the main components detected at the intact TiN surface. $\mathrm{C}, \mathrm{N}$, and $\mathrm{F}$ can be considered to originate from TiN itself and the binder, which is composed of PVDF, while Ti comes from TiN. After the electrochemical reaction, $\mathrm{Ti}$ could not be detected and the quantity of $\mathrm{F}$ decreased. It is inferred that some sediment covers the surface of the TiN. Instead $\mathrm{Al}, \mathrm{Cl}$, and a trace amount of $\mathrm{Na}$ were observed. $\mathrm{Na}$ and $\mathrm{Cl}$ could have resulted from $\mathrm{NaCl}$ and $\mathrm{NH}_{4} \mathrm{Cl}$, as we have seen in the above XRD experiments. Furthermore, it is deduced that even though $\mathrm{Al}(\mathrm{OH})_{3}$ could not be detected by $\mathrm{XRD}$, a trace amount of $\mathrm{Al}$ that originates from the byproducts of the electrochemical reaction was detected via EDS analysis. This coincides with our previous study in which we also detected trace amounts of $\mathrm{Al}$ in our XPS measurement. ${ }^{27}$

Fig. 6 shows the XPS analysis of the surface of the TiN air cathode before and after the electrochemical reaction. Note that $\mathrm{CD}$ indicates the charge-discharge electrochemical reaction as in the XRD section. Fig. 6(a) is the wide-range spectra of TiN before and after the electrochemical reaction. Fig. 6(b) and (c) are the XPS results for Ti $2 p$ and $\mathrm{N}$ 1s, respectively. Obvious differences are noted in the disappearance of the Ti 2p peak and the emergence of $\mathrm{Al} 2 \mathrm{p}$ and $\mathrm{Cl} 2 \mathrm{p}$ peaks. As we observed with the EDS analysis, the Ti atomic orbital could not be seen in the XPS measurement either. This result also shows that the surface of the TiN air cathode is covered with other sediments such $\mathrm{NaCl}$ and $\mathrm{NH}_{4} \mathrm{Cl}$ after the electrochemical reaction; this is shown by the XRD analysis. In addition, $\mathrm{Al} 2 \mathrm{p}$ seems to have originated from Al-collated compounds such as $\mathrm{Al}(\mathrm{OH})_{3}$ or $\mathrm{AlCl}_{3}$, even though these were not clearly observed from the XRD analysis. $\mathrm{Cl}$ $2 \mathrm{p}$ might have resulted from $\mathrm{NaCl}, \mathrm{NH}_{4} \mathrm{Cl}$, or $\mathrm{AlCl}_{3}$. This phenomenon also agrees with the EDS analysis discussed above. Furthermore, as indicated by the changes in the $\mathrm{N} 1 \mathrm{~s}$ peaks, nitrogen exists as TiN before the electrochemical reaction. After the electrochemical reaction, the $\mathrm{N} 1 \mathrm{~s}$ atom orbital exists as an organic compound. One of the suggested organic compounds in which this may exist is $\mathrm{NH}_{4} \mathrm{Cl}$, as it was observed via $\mathrm{XRD}$; however, it should be noted that this is only a speculation.

Both metal nitride and carbide have been reported to be excellent catalysts for the oxygen reduction and evolution reactions. It is thought that at the TiN surface, peroxide formation involves the production of an intermediate superoxide ion $\left(\mathrm{O}_{2}{ }^{-}\right)$, which is followed by protonation and electron transfer to produce $\mathrm{H}_{2} \mathrm{O}_{2}$. However, it has also been shown that TiN may catalyze either two or four electrons for the reduction of oxygen, which is beneficial for catalytic use in metal-air batteries. ${ }^{41}$

$2 \mathrm{e}^{-}$pathway

$$
\begin{gathered}
\mathrm{O}_{2}+2 \mathrm{H}^{+}+2 \mathrm{e}^{-} \rightarrow 2 \mathrm{H}_{2} \mathrm{O}_{2} \\
\mathrm{H}_{2} \mathrm{O}_{2}+2 \mathrm{H}^{+}+2 \mathrm{e}^{-} \rightarrow 2 \mathrm{H}_{2} \mathrm{O}
\end{gathered}
$$

Direct $4 \mathrm{e}^{-}$pathway

$$
\mathrm{O}_{2}+4 \mathrm{H}^{+}+4 \mathrm{e}^{-} \rightarrow 2 \mathrm{H}_{2} \mathrm{O}
$$

It should be noted that a similar phenomenon has been observed in the case of lithium-air batteries. It has been reported that a TiC-based air cathode may be used in a lithium-air battery and that it reduces side reactions that result in electrolyte and electrode decomposition when compared with a carbon-based air cathode. In fact, they exhibited better durable battery performance with respect to the decomposition of $\mathrm{Li}_{2} \mathrm{O}_{2}$. They suggest that this stability may originate from the presence of $\mathrm{TiO}_{2}$ on the surface of TiC. ${ }^{42}$ We have also confirmed in our previous study that TiC and TiN did work as air cathodes for aluminum-air batteries and suppress the formation of byproducts. Thus, it could be proposed that similar byproduct formation suppression mechanisms may also occur in this deep-eutectic-based electrolyte system. It was found that some type of aluminum chemical compound was formed in the present aluminum-air battery besides byproducts such as $\mathrm{Al}(\mathrm{OH})_{3}$ or $\mathrm{Al}_{2} \mathrm{O}_{3}$; this compound resulted from the decomposition of the electrolyte. We believe that carbon existed as a carboxy group and not as a carbonate group, thereby suppressing the formation of $\mathrm{Al}(\mathrm{OH})_{3}$ and $\mathrm{Al}_{2} \mathrm{O}_{3} \cdot{ }^{27}$ However, a detailed mechanism study of the TiC air cathode in our aluminum-air battery remains to be further investigated.

Fig. 7 shows the morphological observation of the surface of the TiN air cathode before and after electrochemical reaction. Fig. 7(b) presents the SEM observation of the TiN air cathode surface after the charge-discharge electrochemical reaction. As compared with Fig. 7(a), which shows the intact TiN air cathode surface, the surface is more rigid and some aggregate forms that are inferred to accumulate during the charge-discharge electrochemical reaction are visible. These aggregations and sedimentation compounds may be enriched on the surface, since we could not detect any atomic orbital of the Ti atom by EDS or XPS. We intentionally eliminated at least $5 \mathrm{~nm}$ of the surface layer of the TiN air cathode using an $\mathrm{Ar}^{+}$ion beam before XPS measurement in order to avoid contamination effects on the measurement. This indicates that the sediments are at least thicker than $5 \mathrm{~nm}$ on the surface of the cathode. It is interesting to note that our aluminum-air battery is stable even after the TiN air cathode has been covered by these layers of sedimentation. It is likely that once the electrode is covered with this kind of stable layer, the aluminum-air battery becomes more stable similar to when the Li ion battery electrode is covered with the solid electrolyte interphase (SEI). This SEI is mainly 

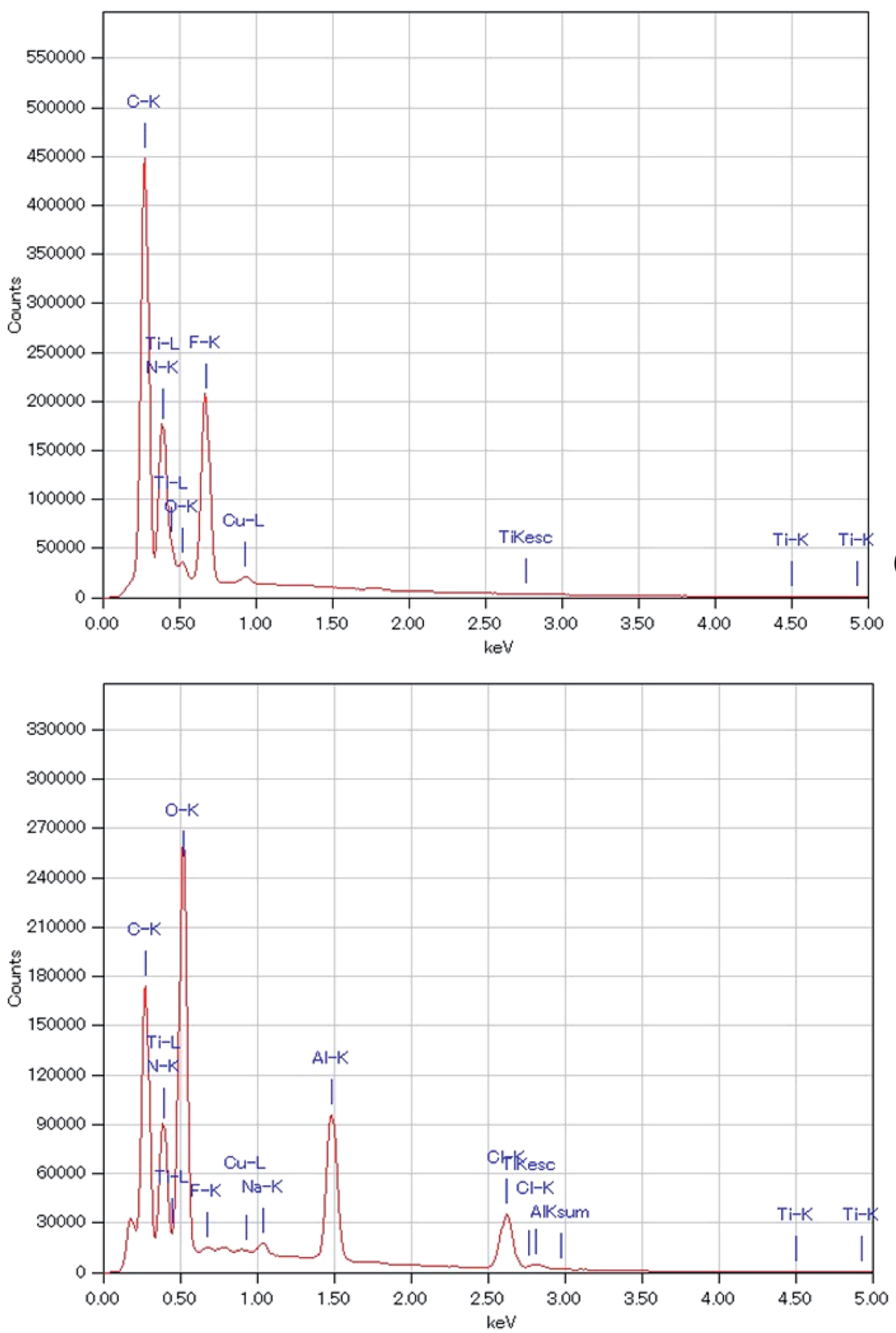

(b)

Fig. 5 EDS of the all solid state Al-air battery TiN air cathode prepared in this study. (a) Intact TiN (b) TiN after the electrochemical reaction.

Table 1 Summarized EDS data of the all solid state Al-air battery TiN air cathode at 2 points, prepared in this study. (a) Intact TiN (b) TiN after the electrochemical reaction

\begin{tabular}{lllll}
\hline Sample & TiN new & TiN new & TiN after CD & TiN after CD \\
Spot & Spot-1 & Spot-2 & Spot-1 & Spot-2 \\
C & 27.98 & 28.75 & 14.68 & 23.56 \\
N & 23.35 & 22.85 & 20.63 & 25.19 \\
O & 2.89 & 2.87 & 25.43 & 30.73 \\
F & 19.86 & 20.06 & 0.52 & 0.14 \\
Na & ND & ND & 0.79 & 0.56 \\
Al & ND & ND & 12.25 & 8.25 \\
Cl & ND & ND & 25.46 & 11.52 \\
Ti & 25.7 & 25.24 & ND & ND
\end{tabular}

composed of $\mathrm{Li}$ and organic chemical compounds and results from the decomposition of the electrolyte during the electrochemical reaction. ${ }^{\mathbf{4 3 , 4 4}}$ One could suggest that this layer on the TiN air cathode could be $\mathrm{NaCl}$ and $\mathrm{NH}_{4} \mathrm{Cl}$ from our experimental results described above. From our previous study, when we applied $\mathrm{Al}_{2}\left(\mathrm{WO}_{3}\right)_{4}$ as an internal layer between the anode and air cathode, we found that $\mathrm{Na}_{2}\left(\mathrm{WO}_{4}\right)\left(\mathrm{H}_{2} \mathrm{O}\right)_{2}$ formed on the air cathode after the electrochemical reaction when an aqueous $\mathrm{NaOH}$ electrolyte was used. ${ }^{17}$ This indicates that $\mathrm{Al}$ was replaced with $\mathrm{Na}$ to form $\mathrm{Na}_{2}\left(\mathrm{WO}_{4}\right)\left(\mathrm{H}_{2} \mathrm{O}\right)_{2}$. However, the crystalline phase would not change just by adsorbing metallic ions onto the surface of the cathode from the electrolyte. We suggest this phenomenon to be similar to the electrochemical doping procedure that Adachi et al. discovered previously for inorganic 


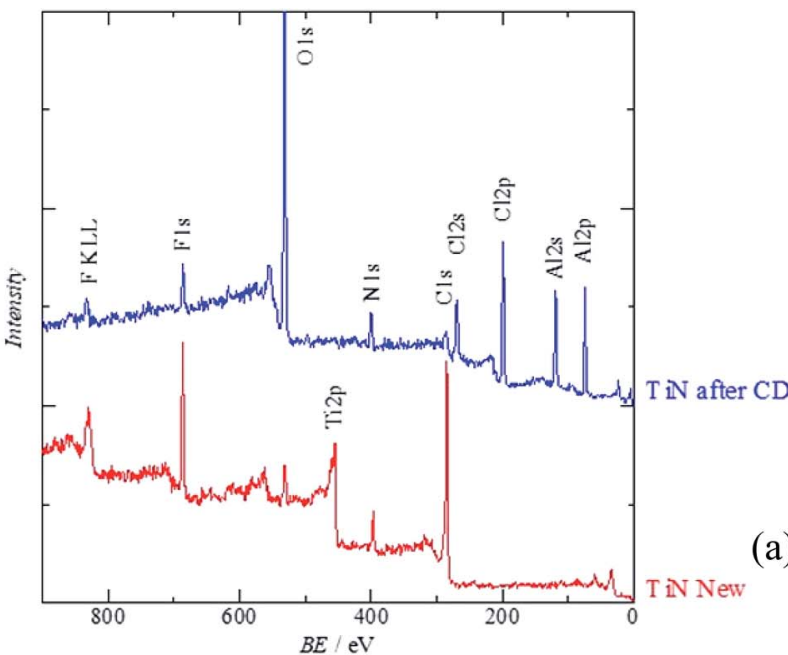

(a)

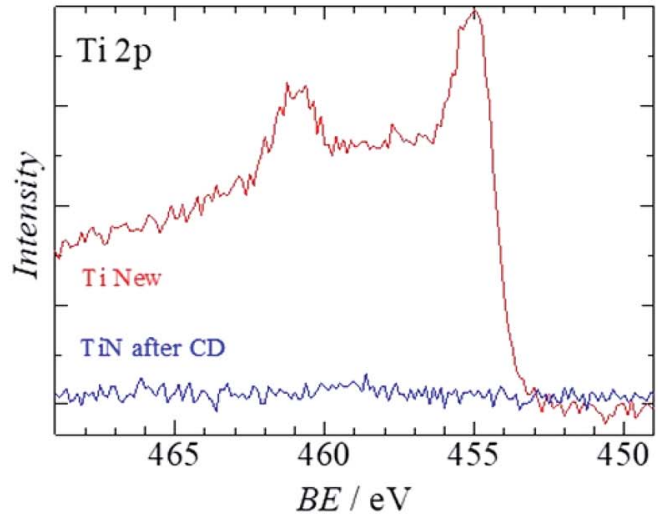

(b)

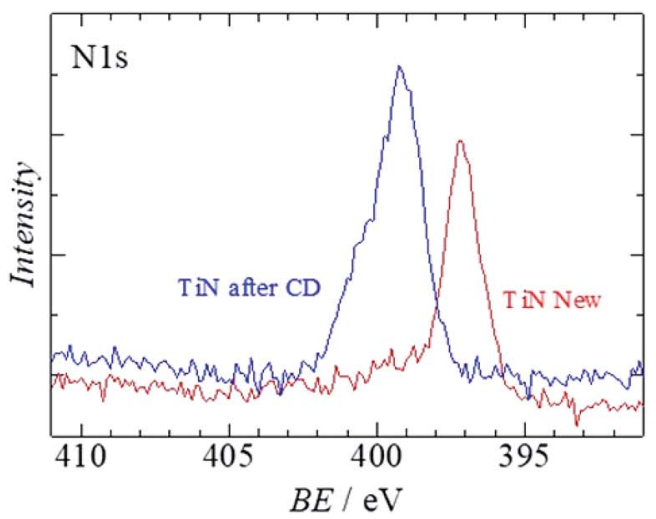

(c)

Fig. 6 XPS of the all solid state Al-air battery TiN air cathode prepared in this study. (a) Wide scan XPS (b) Al 2p (c) Cl 2p.

oxide materials. ${ }^{45}$ We also observed a similar phenomenon in our previous study that in addition to having $\mathrm{Al}_{2} \mathrm{O}_{3}$ as a byproduct of the aluminum-air battery, $\mathrm{Na}_{2} \mathrm{Al}_{22} \mathrm{O}_{34} \cdot 2 \mathrm{H}_{2} \mathrm{O}$ was observed when aqueous $\mathrm{NaOH}$ was used as an electrolyte. On top of that, $\mathrm{K}_{2} \mathrm{Al}_{22} \mathrm{O}_{34}$ was also detected when aqueous $\mathrm{KOH}$ was used as an electrolyte. As Na- and K-containing complex phases appeared, a Na- and K-containing ion had been participating in the electrochemical reaction in our aluminum-air battery system. ${ }^{46}$ Likewise, $\mathrm{NaCl}$ and $\mathrm{NH}_{4} \mathrm{Cl}$ formed through some unknown mechanism that is unknown at this stage by replacing $\mathrm{Al}$ with $\mathrm{Na}$. It could also be deducted that since CMC was
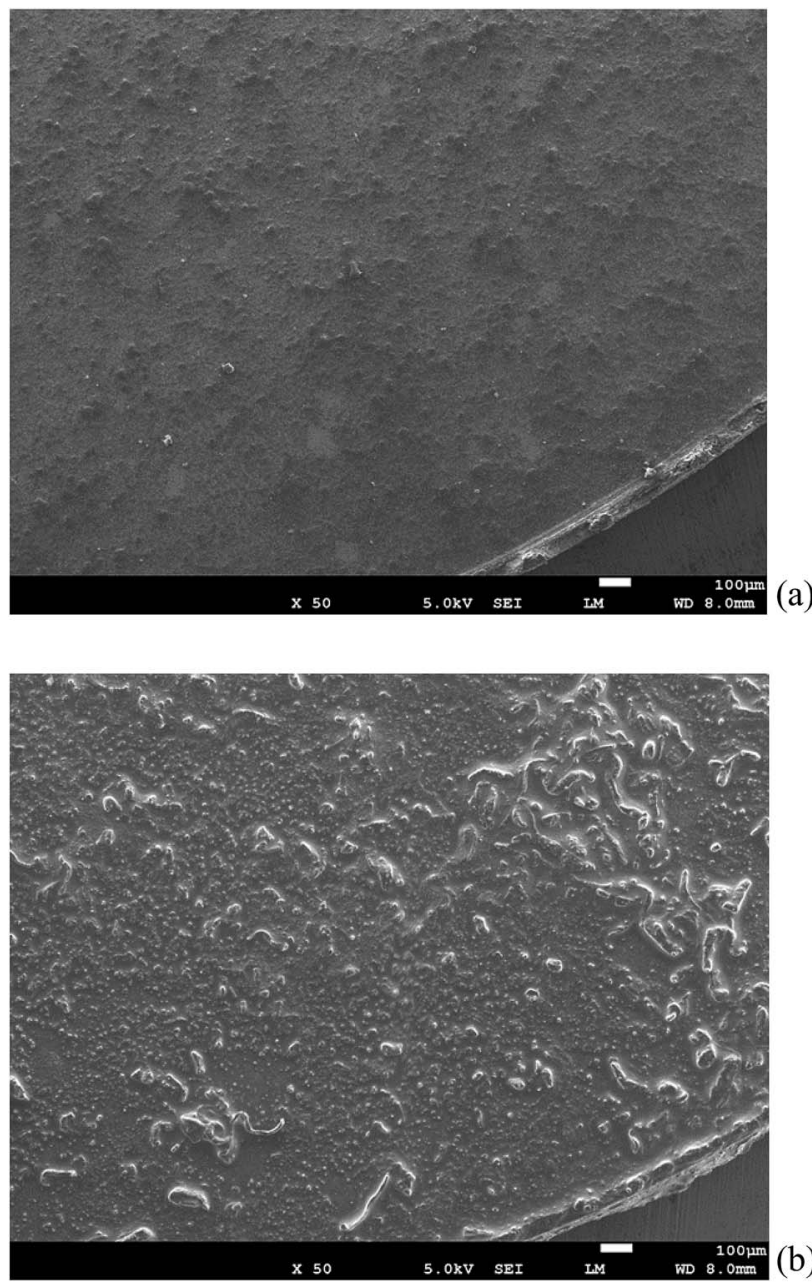

Fig. 7 SEM observation of the all solid state Al-air battery TiN air cathode prepared in this study. (a) Intact TiN (b) TiN after the electrochemical reaction.

generally partly modified with sodium, sodium was replaced with $\mathrm{AlCl}_{3}$ to form $\mathrm{NaCl}$.

Either way, a detailed investigation must be carried out in order to create a stable, rechargeable aluminum-air battery with improved performance.

\section{Conclusion}

A solid-state rechargeable aluminum-air battery with a solid electrolyte composed of $\mathrm{AlCl}_{3}$, urea, CMC, and glycerin was fabricated. The battery exhibited stable electrochemical reactions as confirmed by the charge-discharge curves and cyclic voltammogram. When TiN was used as an air cathode material, the typical byproducts of an aluminum-air battery such as $\mathrm{Al}(\mathrm{OH})_{3}$ and $\mathrm{Al}_{2} \mathrm{O}_{3}$ were not observed even when a deep-eutectic solvent-based electrolyte was used as an electrolyte. As far as we know, this is the first time that byproducts have not been observed on either the $\mathrm{Al}$ anode or the air cathode when a deepeutectic solvent-based electrolyte was used. EDS, XPS, and SEM analysis revealed that the TiN air cathode surface was covered with a layer that did not hinder the electrochemical reaction. 


\section{Conflicts of interest}

There are no conflicts to declare.

\section{Acknowledgements}

The author wishes to express thanks to Mr Kazuo Sakai and Dr Hideki Yoshioka for helpful discussions.

\section{References}

1 Y. Chen, L. Zhang, Y. Zhang, H. Gaoa and H. Yan, RSC Adv., 2018, 8, 10489-10508.

2 P. Chandran, A. Ghosh and S. Ramaprabhu, Sci. Rep., 2018, 8, 3591-3601.

3 N. Minh, J. Mizusaki and S. C. Singhal, ECS Trans., 2017, 78, 63-73.

4 S. Twaha, J. Zhu, Y. Yan and B. Li, Renewable Sustainable Energy Rev., 2016, 65, 698-726.

5 G. E. Blomgren, J. Electrochem. Soc., 2017, 164, A5019-A5025. 6 A. Mauger and C. M. Julien, Ionics, 2017, 23, 1933-1947.

7 W. Xue, et al., Nat. Energy, 2019, 4, 374-382.

8 D. Xiaoli, et al., Sci. Adv., 2016, 2, 1501038-1501045.

9 H. Notohara, K. Urita, H. Yamamura and I. Moriguchi, Sci. Rep., 2018, 8, 8747-8753.

10 A. Manthiram, Chem. Rev., 2014, 114, 11751-11787.

11 J. Y. Hwang, S. T. Myung and Y. K. Sun, Chem. Soc. Rev., 2017, 46, 3529-3614.

12 T. Zhang, Z. Tao and J. Chen, Mater. Horiz., 2014, 1, 196-206. 13 F. Cheng and J. Chen, Chem. Soc. Rev., 2011, 41, 2172-2192. 14 H. Pan, et al., Nat. Energy, 2016, 1, 16039.

15 H. Yadegari, Chem. Mater., 2015, 27, 3040-3047.

16 J. Kim, et al., Nat. Commun., 2016, 7, 10670.

17 C. Xia, et al., Nat. Chem., 2015, 7, 496-501.

18 E. Egan, et al., J. Power Sources, 2013, 236, 293-310.

19 Q. Li \&N. Bjerrum, J. Power Sources, 2002, 110, 1-10.

20 R. Mori, RSC Adv., 2013, 3, 11547-11551.

21 R. Mori, RSC Adv., 2014, 4, 1982-1987.

22 R. Mori, RSC Adv., 2014, 4, 30346-30351.
23 R. Revel, T. Audichon and S. Gonzalez, J. Power Sources, 2014, 272, 415-421.

24 D. Gelman, B. Shvartsev and Y. Ein-Eli, J. Mater. Chem. A, 2014, 2, 20237-20242.

25 H. Wang, et al., ACS Appl. Mater. Interfaces, 2016, 8, 2744427448.

26 R. Mori, $R S C$ Adv., 2017, 7, 6389-6395.

27 R. Mori, Sustainable Energy Fuels, 2017, 1, 1082-1089.

28 R. Mori, ECS Trans., 2017, 80, 377-393.

29 R. Mori, Phys. Chem. Chem. Phys., 2018, 20, 29983-29988.

30 M. Angell, et al., Proc. Natl. Acad. Sci. U. S. A., 2017, 114, 834839.

31 N. Bogolowski and J. F. Drille, Electrochim. Acta, 2018, 274, 353-358.

32 M. Kar, T. J. Simons, M. Forsythac and D. R. MacFarlane, Phys. Chem. Chem. Phys., 2014, 16, 18658-18674.

33 L. Qingfeng, H. A. Hjuler, R. W. Berg and N. J. Bjerrum, J. Electrochem. Soc., 1990, 137, 2794-2798.

34 N. Takami and N. Koura, Electrochim. Acta, 1988, 33, 11371142.

35 R. Huglen, et al., Inorg. Nucl. Chem. Lett., 1978, 14, 167-172. 36 Q. X. Qin and M. S. Kazacos, J. Electroanal. Chem. Interfacial Electrochem., 1984, 168, 193-206.

37 H. M. A. Abood, A. P. Abbott, A. D. Ballantynea and K. S. Rydera, Chem. Commun., 2011, 47, 3523-3525.

38 Y. Katayama, et al., Electrochemistry, 2018, 86, 42-45.

39 M. L. Agiorgousis, Y. Y. Sun and S. Zhang, ACS Energy Lett., 2017, 2, 689-693.

40 Y. Chen, et al., Phys. Chem. Chem. Phys., 2019, 21, 1181011821.

41 R. Ohnishi, et al., J. Electrochem. Soc., 2013, 160, F501-F506. 42 M. Muhammed, et al., Nat. Mater., 2013, 12, 1050-1056.

43 B. D. Adams, et al., ACS Nano, 2014, 8, 12483-12493.

44 E. Peled and S. Menkin, J. Electrochem. Soc., 2017, 164, A1703-A1719.

45 N. Imanaka, M. Hiraiwa, S. Tamura and G. Adachi, Electrochem. Solid-State Lett., 1999, 2, 570-571.

46 R. Mori, J. Electrochem. Soc., 2015, 162, A288-A294. 